her, J.J. McCormick, G.P. Taylor and R.J. Klebe. 1998. Overview of matrix metalloproteinase expression in transformed cells. Matrix Biol. 16:483-496.

3.Hill, H.Z., C. Huselton, B. Pilas and G.J. Hill. 1987. Ability of melanins to protect against the radiolysis of thymine and thymidine. Pigment Cell Res. 1:81-86.

4.Kreader, C.A. 1996. Relief of amplification inhibition in PCR with bovine serum albumin or T4 gene 32 protein. Appl. Environ. Microbiol. 62:1102-1106.

5.Yoshii, T., K. Ramura, T. Taniguchi and K.I.I. Akiyama. 1993. Water-soluble eumelanin as a PCR-inhibitor and a simple method for its removal. Jpn. J. Leg. Med. 47:323-329.

This study was supported, in part, by Grant No. DE08144 from the National Institutes of Health. Address correspondence to Dr. Troy A. Giambernardi, Dept. of Cellular and Structural Biology, University of Texas Health Science Center, San Antonio, TX 78284, USA. Internet: giambernard@ uthscsa.edu

Received 6 April 1998; accepted 20 July 1998.

Troy A. Giambernardi, Ulrich Rodeck ${ }^{\mathbf{1}}$ and Robert J. Klebe University of Texas Health Science Center San Antonio, TX ${ }^{I}$ Thomas Jefferson University Philadelphia, PA, USA

\section{Amplification of mRNAs from Single, Fixed, TUNEL-Positive Cells}

\section{BioTechniques 25:566-570 (October 1998)}

The ability to assess the expression of multiple genes in individual cells represents a powerful tool for studying the mRNA abundances within identifiable cell types. The amplified antisense RNA (aRNA) method (4) allows the simultaneous identification of relative messenger RNA (mRNA) levels for multiple genes within single cells. Recently, the aRNA procedure has been extended to characterize the expression of mRNA abundance for multiple genes within immunohistochemically labeled cells (3). This method allows additional phenotypic characterization of cells before single-cell amplification. Whereas this method is useful for identifying cells based on the expression of a particular protein, immunohistochemical detection is problematic for characterizing the genetic profile of degenerating or dying cells. Specifically, a frequent hallmark of damaged cells is disruption of protein turnover. Therefore, particular proteins' expression levels may be decreased or even absent in dying cells (7). The expression of immunohistochemical markers might reveal abnormal cell populations, whereas the expression of certain proteins in cells can be associated with cell death. However, without a specific marker of cell damage, positive identification of damaged/dying cells based on immunohistochemical criteria may be unreliable.

Here, we chose the terminal deoxynucleotidyl-transferase (TdT)-mediated biotinylated (dUTP) nick-endlabeling (TUNEL) technique (9) to identify dying cells in the developing brain. The TUNEL stain uses the enzyme TdT, which incorporates biotinylated nucleotides to the $3^{\prime}$ ends of fragmented DNA, and TUNEL has been used as a marker for dying cells. The TUNEL method is also useful for identifying cells that are undergoing programmed cell death (PCD), which occurs as a consequence of normal development (6). The purpose of this study was to adapt the single-cell aRNA amplification technique for use in TUNEL-positive cells from fixed tissue preparations.

Three Sprague Dawley rat pups at postnatal day $8(\mathrm{P} 8)$ were used. This time point was chosen because PCD in the rat is maximal at P8 (6). Rats were anesthetized and decapitated. Brains were post-fixed in situ in $4 \%$ paraformaldehyde for 3-4 h before removal of the brain, which was then immersion-fixed for an additional $24 \mathrm{~h}$. After fixation, brains were embedded in paraffin and cut into $6-\mu \mathrm{m}$ sections. TUNEL was performed using previously described methods (9). Figure 1 presents an example of a TUNEL-positive cell selected for dissection and subsequent aRNA amplification. Apoptotic cells selected for analysis were detected based on the presence of at least two of the following characteristic features of apoptosis: cell shrinkage, membrane blebbing or intense nuclear and cytoplasmic staining. Briefly, coronal sections were adhered to poly-L-lysinecoated slides by brief heat treatment at $60^{\circ} \mathrm{C}$ for 15 min. After removal of paraffin and rehydration, the tissue was digested for $15 \mathrm{~min}$ with $20 \mu \mathrm{g} / \mathrm{mL}$ proteinase K (Sigma Chemical, St. Louis, MO, USA). The reaction was terminated with tap water, and the tissue was preincubated in Buffer A $(25 \mathrm{mmol} / \mathrm{L}$ Tris- $\mathrm{HCl}, \mathrm{pH}$. 6.6, containing 200 $\mathrm{mmol} / \mathrm{L}$ potassium cacodylate and 0.25 $\mathrm{mg} / \mathrm{mL}$ bovine serum albumin) for at least $5 \mathrm{~min}$. Sections were incubated at $37^{\circ} \mathrm{C}$ with labeling solution containing TdT (0.3 U/mL), biotinylated-16-dUTP (20 mmol/L; Boehringer Mannheim, Indianapolis, IN, USA) and $1.5 \mathrm{mmol} / \mathrm{L}$ cobalt chloride in Buffer A for $1 \mathrm{~h}$ in a humidified chamber. The reaction was terminated with $2 \times$ SSC ( $300 \mathrm{mM}$ sodium chloride and $30 \mathrm{mM}$ sodium citrate, $\mathrm{pH}$ 7.4). After vigorous washing with $0.1 \mathrm{M}$ Tris, $\mathrm{pH} 7.4$, the sections were blocked with $10 \%$ goat serum in $0.1 \mathrm{M}$ Tris for $30 \mathrm{~min}$. The labeled DNA was visualized by treating the tissue with a 1:40 dilution of streptavidin-conjugated alkaline phosphatase (BioGenex, San Ramon, CA, USA) and stained with Fast Red $^{\mathrm{TM}}$ Tablets (Sigma Chemical). Sections were stored in diethyl pyrocarbonate (DEPC)-treated distilled (d) $\mathrm{H}_{2} \mathrm{O}$ until further processing.

Following TUNEL, sections were placed in a humidified chamber and incubated in a mixture of $50 \%$ formamide, $5 \times$ SSC, DEPC-treated $\mathrm{dH}_{2} \mathrm{O}$ and an oligo(dT) primer coupled to a

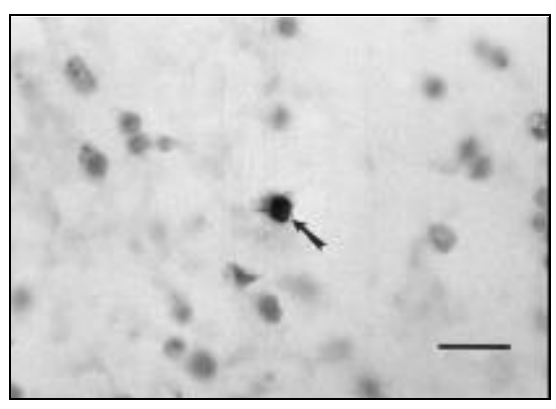

Figure 1. TUNEL-positive cell (arrow) from P8 rat cortex. $(\mathrm{Bar}=20 \mu \mathrm{m})$ Note the presence of two apoptotic markers (cell shrinkage and intense nuclear and cytoplasmic staining). 


\section{Benchmarks}

T7 RNA polymerase promoter sequence [oligo(dT-T7)] that hybridized to cellular poly(A) tail mRNA for $12-$ $18 \mathrm{~h}$ at room temperature. The cDNA was synthesized directly on the section with $0.5 \mathrm{U} / \mathrm{mL}$ avian myeloblastosis virus reverse transcriptase (Seikagaku, St. Petersburg, FL, USA) in in situ transcription (IST) reaction buffer $(50 \mathrm{mM}$ Tris- $\mathrm{HCl}, \mathrm{pH} 8.3,6 \mathrm{mM} \mathrm{MgCl}_{2}, 120$ $\mathrm{mM} \mathrm{KCl}, 7 \mathrm{mM}$ dithiothreitol, $250 \mu \mathrm{M}$ each dATP, dCTP, dGTP, TTP and $\mathrm{RNasin}^{\circledR}$ at $\left.0.12 \mathrm{U} / \mathrm{mL}\right)$. Sections were then washed for $8-12 \mathrm{~h}$ in $0.5 \times \mathrm{SSC}$.

After TUNEL and IST, individual TUNEL-positive cells ( $n=2-3$ cells per slice) from the cortex were viewed under 40× magnification and dissected away from the tissue section by using a micromanipulator and aspirated gently into glass microelectrodes (3). Following second-strand synthesis of DNA, the mRNA from cells was amplified with T7 RNA Polymerase (Epicentre Technologies, Madison, WI, USA) incorporating [ $\left.{ }^{32} \mathrm{P}\right] \mathrm{CTP}(4)$. The aRNA then served as a template for the steps associated with a second round of amplification. The second-round radiolabeled aRNA was used to probe reverse Northern (slot) blots. To detect particular mRNAs present in single TUNELpositive cells, reverse Northern blotting was performed using linearized plasmid cDNAs. We chose an array of cDNAs that would reflect a sample of the mRNAs found in developing cells. These included the synthetic enzyme glutamic acid decarboxylase (GAD65), nestin, $\alpha$-internexin, nerve growth factor (NGF), nerve growth factor receptor (NGFR), tyrosine kinase receptor (TrkA), glial fibrillary acidic protein (GFAP), high-molecular-weight neurofilament (NF-H) and Bcl-2. Hybond ${ }^{\circledR}$ $\mathrm{N}$ nylon membranes (Amersham Pharmacia Biotech, Piscataway, NJ, USA) were loaded with $0.5 \mu \mathrm{g}$ of each cDNA. Blots were first incubated in prehybridization solution containing $50 \%$ formamide, $6 \times$ standard saline phosphate EDTA (SSPE), 5× Denhardt's, $200 \mu \mathrm{g} / \mathrm{mL}$ salmon sperm DNA and $0.1 \%$ sodium dodecyl sulfate (SDS) for $24 \mathrm{~h}$ at $42^{\circ} \mathrm{C}$. Blots were then probed with $\left.{ }^{32} \mathrm{P}\right] \mathrm{CTP}$-labeled aRNA in hybridization buffer from individual cells and hybridized at $42^{\circ} \mathrm{C}$ for $48 \mathrm{~h}$. Blots were washed in $2 \times \mathrm{SSC}$ with $0.1 \% \mathrm{SDS}$
( $2 \times 15 \mathrm{~min}$ ) and then washed in $0.2 \times$ SSC with $0.1 \%$ SDS for $1 \mathrm{~h}$. Blots were apposed to Kodak film (Eastman Kodak, Rochester, NY, USA) for 48-72 h.

Here, we demonstrate that mRNAs from single, fixed TUNEL-positive cells can be successfully amplified. The mRNAs for nestin, NGF, GAD65 and Bcl-2 were detected in cells undergoing PCD (Figure 2). As has been reported previously, the mRNA encoding the anti-apoptotic proto-oncogene, Bcl-2, was also detected in immature cortical cells (2). In contrast, the mRNAs for GFAP, NF-H, NGFR and TrkA were not detected in TUNEL-stained cells from the present study. While an absence of mRNA for these genes is possible, some mRNAs may not be accessible by the current technique. However, the size distribution of the aRNA products from the second round of amplification ranged from $300 \mathrm{bp}$ to more than $2 \mathrm{~kb}$ in length. In addition, the size of aRNA from TUNEL-positive cells was similar to aRNA generated from surrounding unlabeled cortical cells, confirming that aRNA amplification was equally efficient in TUNEL-positive and TUNEL-negative cells (data not shown). Thus, the mRNAs from TUNEL-positive cells are not adverse-

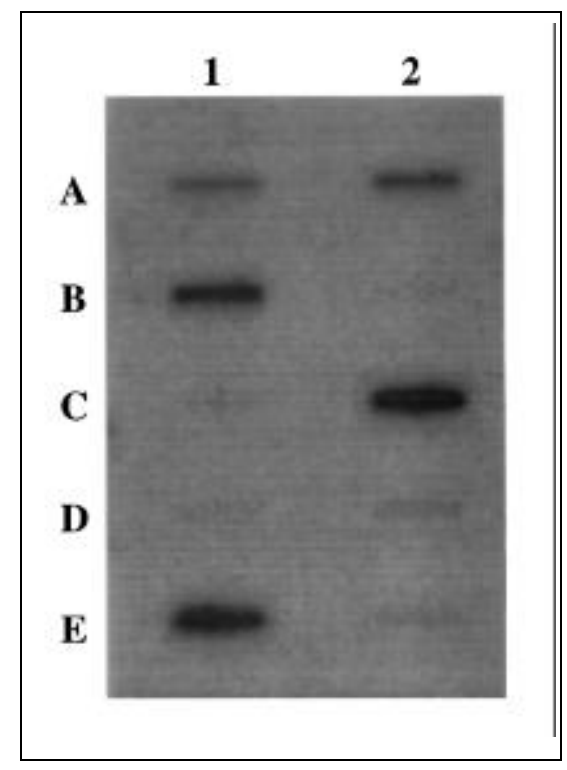

Figure 2. Representative slot blot generated from a TUNEL-positive cell from P8 rat cortex. The slot blot contained the following cDNAs. A1: Bluescript ${ }^{\circledR}$ vector; A2: nestin; B1: GAD65; B2: $\alpha$ internexin; C1: GFAP; C2: NGF; D1: NF-H; D2: NGFR; E1: Bcl-2 and E2: TrkA. 
ly affected by the TUNEL protocol, and the aRNA made from TUNELstained cells can be amplified with product sizes similar to those previously reported for immunohistochemically labeled cells (3).

The ability to analyze multiple genes in TUNEL-stained cells offers a distinct advantage for the study of molecular mechanisms contributing to cell death. The TUNEL method eliminates problems associated with immunohistochemical labeling of damaged cells due to decreased synthesis and/or altered turnover of proteins associated with disease (5). Furthermore, cellular immunohistochemical changes may parallel, but do not unequivocally indicate, cell damage. By specifically labeling fragmented DNA, TUNEL confirms the presence of dying and/or dead cells. Other histological stains have been used to identify damaged cells (1); however, it is not known what particular cell damage marker is labeled by these stains, whereas TUNEL is an unambiguous marker of cell damage. TUNEL histochemistry offers the unique opportunity to study the regional localization and progression of PCD in developing organisms. Moreover, TUNEL coupled with single-cell aRNA amplification may lead to the identification of molecular contributors to PCD. Another advantage of combining TUNEL with aRNA technology is the possibility of studying the molecular pathology of apoptotic and non-apoptotic (necrotic) cells. The TUNEL stain labels both types of cell death and, based on morphological differences, these two types of cell death can be distinguished (9). While we assessed a limited number of genes in cells undergoing PCD, the aRNA amplification technique offers the possibility of analyzing simultaneously mRNA abundances encoding for numerous genes (4). The current application of aRNA amplification in TUNEL-positive cells permits a temporal analysis of coordinated gene expression in single cells in vivo. The presence of TUNEL reactivity has recently been described following a variety of central nervous system (CNS) insults such as stroke, traumatic brain injury and Alzheimer's disease (8-10). The successful amplification of mRNAs from TUNEL-stained cells can provide valuable information about the molecular events contributing to cell death. This information may lead to the development of novel therapeutic approaches for various neurological insults and diseases in which TUNEL reactivity has been detected.

\section{REFERENCES}

1.Auer, R.N., H. Kalimo, Y. Olsson and B.K. Siesjo. 1985. The temporal evolution of hypoglycemic brain damage. Acta Neuropathol. 67:13-24.

2.Castren, E., Y. Ohga, M.P. Berzaghi, G. Tzimagiorgis, $H$. Thoenen and D. Lindholm. 1994. Bcl-2 messenger RNA is localized in neurons of the developing and adult rat brain. Neuroscience 61:165-177.

3.Crino, P.B., J.Q. Trojanowski, M.A. Dichter and J. Eberwine. 1996. Embryonic neuronal markers in tuberous sclerosis: single-cell molecular pathology. Proc. Natl. Acad. Sci. USA 93:14152-14157.
4.Eberwine, J., H. Yeh, K. Miyashiro, Y. Cao, S. Nair, R. Finnell, M. Zettel and P. Coleman. 1992. Analysis of gene expression in single live neurons. Proc. Natl. Acad. Sci. USA 89:3010-3014.

5.Ferrer, I., T. Tunon, E. Soriano, A. del Rio, I. Iraizoz, M. Fonseca and N. Guionnet. 1993. Calbindin D-28k immunoreactivity in the temporal neocortex in patients with Alzheimer's disease. Clin. Neuropathol. 12:53-58.

6.Fung, K., VM-Y. Lee and J.Q. Trojanowski. 1995. Dynamics of cell proliferation and cell death during the emergence of primitive neuroectodermal tumors of the immature central nervous system in transgenic mice. Am. J. Pathol. 146:1376-1387.

7.Hicks, R.R., D.H. Smith and T.K. McIntosh. 1995. Temporal response and effects of excitatory amino acid antagonism on microtubuleassociated protein 2 immunoreactivity following experimental brain injury in rats. Brain Res. 678:151-160.

8.Linnik, M.D., J.A. Miller, J. Sprinkle-Cavallo, P.J. Mason, F.Y. Thompson, L.R. Montgomery and K.K. Schroeder. 1995. Apoptotic DNA fragmentation in the rat cerebral cortex induced by permanent middle cerebral artery occlusion. Mol. Brain Res. 32:116-124.

9.Rink, A., K. Fung, J.Q. Trojanowski, VMY. Lee, E. Neugebauer and T.K. McIntosh. 1995. Evidence of apoptotic cell death after experimental traumatic brain injury in the rat. Am. J. Pathol. 147:1575-1583.

10.Troncoso, J.C., R.R. Sukhov, C.H. Kawas and V.E. Koliatsos. 1996. In situ labeling of dying cortical neurons in normal aging and in Alzheimer's disease: correlations with senile plaques and disease progression. J. Neuropathol. Exp. Neurol. 55:1134-1142.

This work was supported by NIH Grant No. AG9900 (J.H.E.) and NIH Grant Nos. RO1-NS26818 and PO1-NS08803 and a Merit Review Grant from the Veterans Administration (T.K.M.). Address correspondence to Dr. Tracy K. McIntosh, University of Pennsylvania, Department of Neurosurgery, 3320 Smith Walk, Hayden Hall Room 105C, Philadelphia, PA 19104, USA. Internet: mcintosh@eniac.seas.upenn.edu

Received 29 April 1998; accepted 7 July 1998.
D.M. O'Dell, R. Raghupathi, P.B. Crino, B. Morrison III, J.H. Eberwine and T.K. McIntosh University of Pennsylvania School of Medicine Philadelphia, PA, USA 